\title{
REVIEW
}

\section{Coronary intervention in cancer patients: the need for personalized cardiac care}

\author{
David L. Boone', Saradadevi Thanikachalam², Frances Cervoni-Curet', Dinu-Valentin Balanescu², \\ Teodora Donisan ${ }^{3}$, Gloria lliescu ${ }^{4}$, Nicolas Palaskas ${ }^{4}$, Juan Lopez-Mattei ${ }^{4}$, Mehmet Cilingiroglu ${ }^{5}$, \\ Konstantinos Marmagkiolis ${ }^{6}$, Cezar Iliescu ${ }^{4}$
}

\section{BACKGROUND}

Since 1999, we have witnessed significant improvements in both cancer and cardiovascular care, translating into decreased mortality in both disease processes during the initial decade of the century. Since $201 \mathrm{I}$, the parallel improvement in survivorship in both groups diverged, with cancer survivorship continuing to improve (with an overall decrease of $19 \%$ ) while cardiovascular survivorship witnessed a $4 \%$ increase in mortality as opposed to the $22 \%$ reduction seen in the first decade'. Prevention of cardiovascular disease (CVD) has been a main focus of current cardiovascular research, since $>80 \%$ of CVD is thought to be potentially prevented based on aggressive modification of traditional cardiovascular risk factors ${ }^{2}$. Aggressive modification of same risk factors has been shown to decrease the incidence of cancer $^{3}$. Despite efforts to decrease the prevalence of both diseases, cancer and heart disease continue to be the leading causes of death of middle-aged adults and represent $50 \%$ of all deaths in this age group. It is evident that the same risk factors drive molecular pathways toward concomitant expression of both diseases ${ }^{4}$. Investigations to the association between cancer and cardiovascular disease as a comorbid group has been limited to few studies as previous research trends focused on a single cause and effect paradigm ${ }^{4-11}$. This has driven further research into the comorbid conditions that afflict those with cancer as evidenced by a high number of percutaneous coronary interventions ( $\mathrm{PCl}$ ) in those with a cancer history ${ }^{13}$. However, more clinical data recognizes the increased use of $\mathrm{PCl}$ in cancer patients

\footnotetext{
' University of Texas Health Science Center - Houston

${ }^{2}$ John P. Hussmann Institute for Human Genomics, University of Miami Miller School of Medicine, Miami, FL 33I36, USA

${ }^{3}$ Department of Internal Medicine, Beaumont Health, Royal Oak, Michigan

${ }^{4}$ Anderson Cancer Center, University of Texas, Houston, TX, USA

${ }^{5}$ Bahçeșehir University

${ }^{6}$ St. Joseph's Hospital-Tampa, Tampa, FL
}

as reflected in the Nationwide Inpatient Sample (NIS) database, while majority of randomized clinical trials continue to have cancer as exclusion criteria and indirectly lead to a paucity of evidence that can be used to make life-saving clinical decisions in cancer patients with CVD. Until recently, the focus of CVD in cancer patients has not lent itself to studying each cancer individually but rather if cancer is present or not. As every cancer patient is unique, recent publications like Potts et al., have evaluation of in-hospital outcomes in patients undergoing $\mathrm{PCl}$ in specific groups (i.e. leukemia, lymphoma) using the Nationwide Inpatient Sample (NIS); leukemia patients had a $40 \%$ increase in the odds of mortality compared to those without leukemia ${ }^{14}$. Identifying the temporal trends in subcategories of cancer diagnoses may better help to understand the effect of $\mathrm{PCl}$ in cancer patients. Overall, revascularization is the treatment of choice for acute coronary syndrome in cancer patients and continued efforts should be made to evaluate the effectiveness and safety of these techniques in those with different cancer types.

\section{CANCER VS. NON-CANCER}

\section{Unique Characteristics of Cancer Patients}

Not only cancer status, but also individual cancer types play a significant role in the expression of CVD. The two most common cancer types associated with CVD are lung and breast cancer, with $43 \%$ of those with lung cancer having a comorbid association with CVD and up to $17 \%$ of patients with breast cancers ${ }^{15}$. This is

\footnotetext{
$\checkmark$ Contact address:

Cezar Iliescu, MD, Professor of Medicine, Medical Director Cardiac Catheterization Laboratory, Anderson Cancer Center I5I5 Holcombe Boulevard, Houston, Texas, 77030, USA.

E-mail: ciliescu@mdanderson.org
} 
further supported by evidence that has shown patients affected by CVD have a predisposed risk of neoplasia ${ }^{16}$. Also it is extremely relevant if patient is being actively treated for malignancy versus just having a history of malignancy. In a retrospective observational study by Yoon-Park et. al, in the inpatient care of patients with active hematological malignancy, cardiology was involved in $>90 \%$ of acute coronary syndrome cases. Up to $75 \%$ of these cases were managed medically, with only $55 \%$ and $21 \%$ of these patients being managed with ASA and P2Y 12 inhibitors, respectively ${ }^{17}$. This lack of goal directed medical therapy (GDMT), coincides with the lack of standardized data to draw from in these clinical situations as well as the complexity and frailty of cancer patients. The all-cause mortality of patients who had aspirin withheld as part of the treatment algorithm for ACS had $50 \%$ reduction in survival than those who received aspirin irrespective of revascularization. ${ }^{17}$ In a more generalized review of cancer patients, those with thrombocytopenia were two-times less likely to receive aspirin than those with normal platelet counts $^{18}$. The complexity surrounding the treatment of CVD in active cancer can be attributed to cancer patient's frailty and presence of cytopenias (thrombocytopenia, anemia, pancytopenia), concomitant use of antineoplastic therapy, coagulopathy, and promotion of atherosclerosis.

\section{Thrombocytopenia}

The concern of performing $\mathrm{PCl}$ in cancer patients with thrombocytopenia is derived from procedural/ post-procedural bleeding risk and vascular access site complications. In patients with a new diagnosis of malignancy, there was an increased risk of myocardial infarction within the first 6 months of cancer diagnosis with a hazard ratio of 3.0 (I.8-5.0) to I3.I (I0.0-I7.I), driven by cancer stage and with increased incidence in the first month compared to matched controls without cancer, independent of cancer type ${ }^{19}$. The reason for this heightened predisposition to coronary thromboembolism in active cancer patients is unclear but could be secondary to procoagulant factors and endothelial dysfunction.

Thrombocytopenia is frequent in cancer patients, occurring between 10 to $25 \%$ of those with solid tumors which can play a major role in the decision to use antiplatelet agents or perform coronary intervention $^{20}$. The major concern with thrombocytopenia for treatment of ACS in CVD is the increased risk of bleeding in patients who have a pre-existing or developed level of thrombocytopenia during cancer treatment. In regard to those with pre-existing thrombocytopenia, there is some data to support that patients in this clinical scenario are not at an increased risk of bleeding with $16 \%$ of those with thrombocytopenia having developed bleeding while $14 \%$ of patients developed
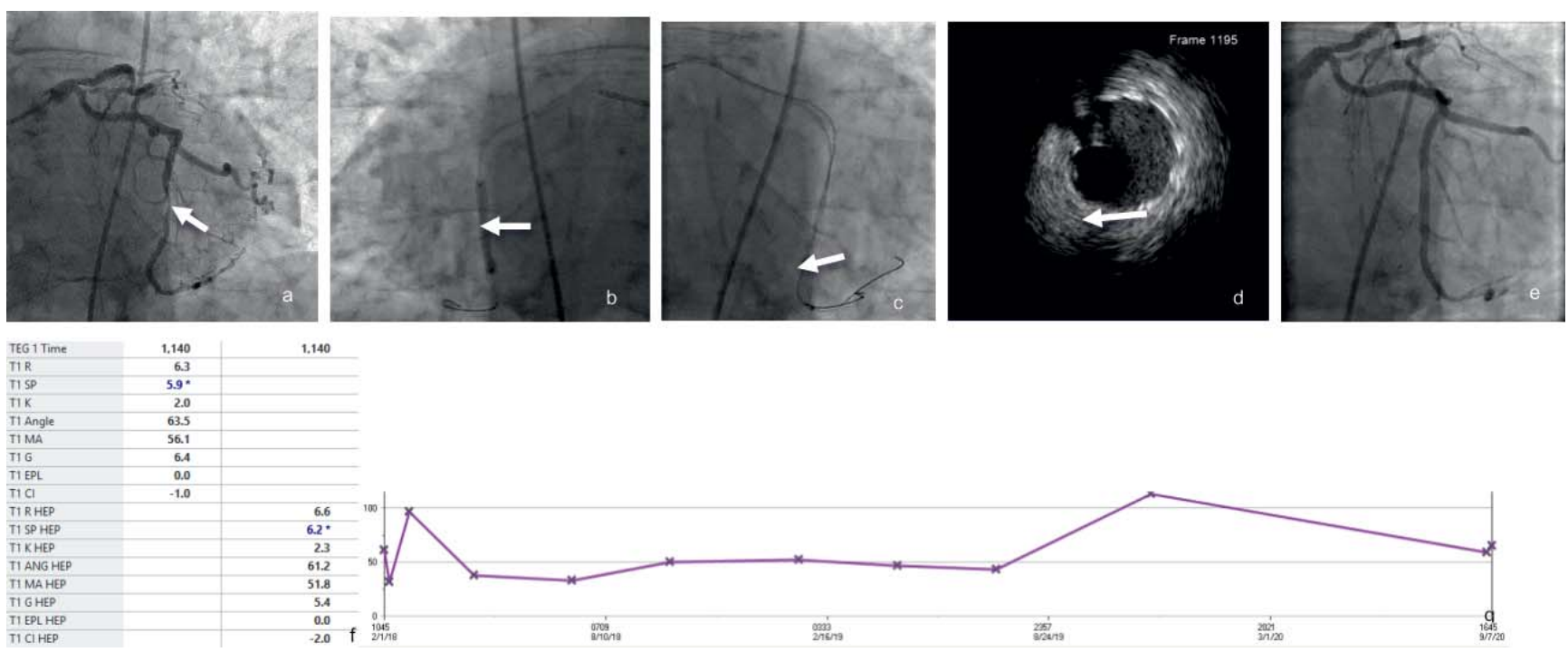

1.140
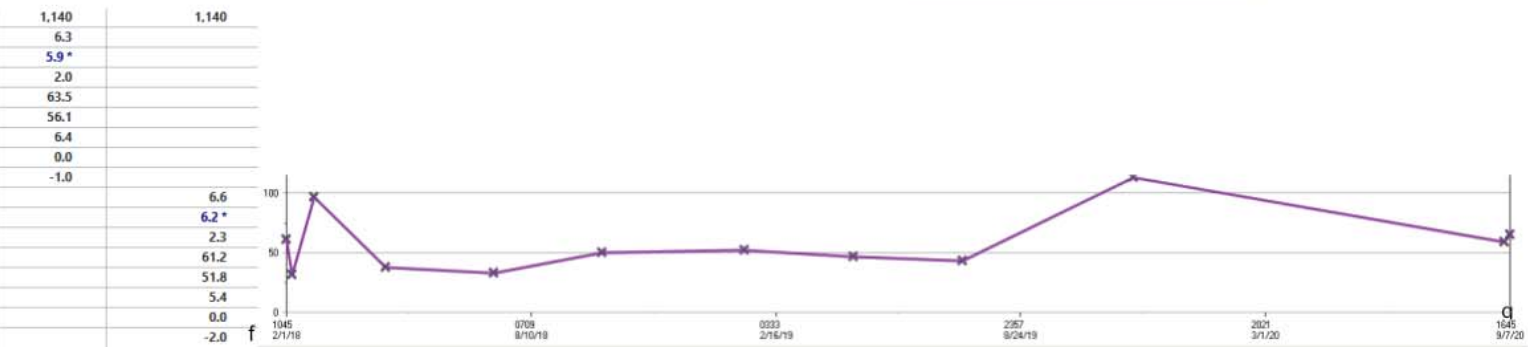

Figure I. 84 yo man with myelodysplastic syndrome (MDS) on a clinical trial with Azacitidine, HTN, CAD sta- tus post LAD PCI, HLD, COPD with worsening fatigue, shortness of breath and abnormal stress test and thrombocytopenia $(65,000 / \mu \mathrm{L})$. Circumflex coronary artery (OM3) tubular calcified lesion $80 \%$ (Fig. Ia) was stented with a Cobra PzF nanocoated stent (NCS) (Fig. Ib), followed by optimization with additional post-dilatation and intravascular ultrasound (IVUS) (Fig. Ic) with excellent angiographic results (Fig. Id). Baseline thrombelastogram was normal (Fig. Ie) despite the low platelet count (Fig. If). 
bleeding in a matched control group without thrombocytopenia $^{21}$. However, this has been challenged more recently with chronic thrombocytopenia being associated with a $40 \%$ increase in the odds of having in hospital bleeding complications as well as in-hospital mortality ${ }^{22}$. However, Society for Cardiovascular Angiography and Interventions (SCAI) expert consensus has established that $\mathrm{PCl}$ can be safely performed on cancer patients with the concurrent use of dual antiplatelet therapy (DAPT) in individuals with platelets as low as $30,000^{23}$. The lack of consistent data amongst thrombocytopenic patients who undergo $\mathrm{PCl}$ leaves operators and providers and knowledge gap can be surmounted by a multidisciplinary team approach and team decision to further pursue revascularization and the use of aspirin and P2YI2 inhibitors.

\section{Cancer Therapy Effects}

Effects of mediastinal radiation

Radiation-induced coronary heart disease (RICHD) has regularly been described in patients with previous mediastinal malignancies such as Hodgkin's Lymphoma and breast cancer, with an estimated risk between $25 \%$ and $250 \%^{24-28}$. The CV risk has a linear dose dependent response with risk increasing by $7.5 \%$ for every additional Grey unit (Gy) exposure ${ }^{29}$. Overtime and with a more insidious onset than traditional coronary disease, patients with prior radiation therapy exposure will manifest in over $50 \%$ of cases with typical anginal symptoms after 10 years or more from exposure ${ }^{30,31}$. Patients presentation for treatment with $\mathrm{PCl}$ for RICHD was at approximately $13+/-10$ years from treatment according to a recent cohort ${ }^{32}$.

While typical anginal symptoms are present in up to two-thirds of patients, the remainder one-third have clinically silent or non-anginal (atypical) chest pain ${ }^{30,31}$. Unlike traditional coronary artery disease, patients with RICHD are relatively younger (mean age of 33 to 65) and will often lack traditional risk factors for coronary artery disease ${ }^{24}$. To make it more challenging, within the first years after radiation exposure, chest pain can be both anginal or non-anginal with as many as half of breast cancer patients experiencing chest pain from chest wall discomfort, pericarditis, and pleuritis ${ }^{24,30,31}$. However, it is critical to rule out acute myocardial infarction in these patients as those treated with higher doses of radiation are more likely to present with acute myocardial infarction and sudden cardiac death with the relative risk of both approaching 4.2 and 6.7 respectively ${ }^{33}$. In a more recent cohort of 157 patients with prior history of radiation, approximately $50 \%$ of patients present with acute coronary syndrome while the other half presented with atypical chest pain or stable angina ${ }^{32}$. These patients with RICHD despite being relatively older than previously reported groups of patients were overall still younger than traditional patients undergoing coronary interventions, with an average age of $65 \pm I I .2$ years. It is a common paradox in these patients between the cardiovascular risk factor burden and the excessive severity of angiographic disease found on diagnostic imaging ${ }^{32}$.

A small propensity matched cohort underwent CTA revealing $59 \%$ of patients with previous XRT exposure had at least one coronary lesion compared to $36 \%$ of controls. The severity of disease was also worse in these patients with $24 \%$ of patients having either three vessel or left main disease and $7 \%$ of all lesions having greater than $70 \%$ of stenosis compared to none with this level of stenosis in the controls ${ }^{34}$. The XRT group had nearly twice as many proximal plaques in all major coronary vessels compared to controls ${ }^{34}$.

Classic location of RICHD are the ostia of LM, LAD, circumflex and RCA. From all patients undergoing $\mathrm{PCI}$ for radiation induced/associated CAD, the LAD was the target lesion for revascularization in up to $52 \%$ of patients with one third of patients having a LM or ostial stenosis ${ }^{32}$. The atypical presentation and complexity of disease can make the appropriate strategy for revascularization challenging. There is evidence supporting the use of CTA to identify lesion severity and location.

The management of patients with XRT has a medical management and revascularization component. The medical management of RICHD is beyond the scope of this review and should overlap with the treatment of traditional coronary artery disease. Revascularization techniques, however, can be divided into surgical and percutaneous revascularization with no randomized controlled trials comparing these two management strategies. However, there are several retrospective cohort studies that evaluated the outcomes of either surgical or percutaneous revascularization without any head-to-head comparisons. PCl in XRT exposed patients leads to a $58 \%$ increase in major adverse cardiovascular and cerebrovascular events (MACCE) after receiving $\mathrm{PCl}$ which includes a $24 \%$ and $38 \%$ increase in all-cause and cardiac mortality, respectively ${ }^{32}$. In a propensity matched cohort, Liang et al. found that there was a non-significant difference in all-cause and CVD mortality ${ }^{35}$. This highlights the limitations of the collected data, not reflecting the radiation dose to the 

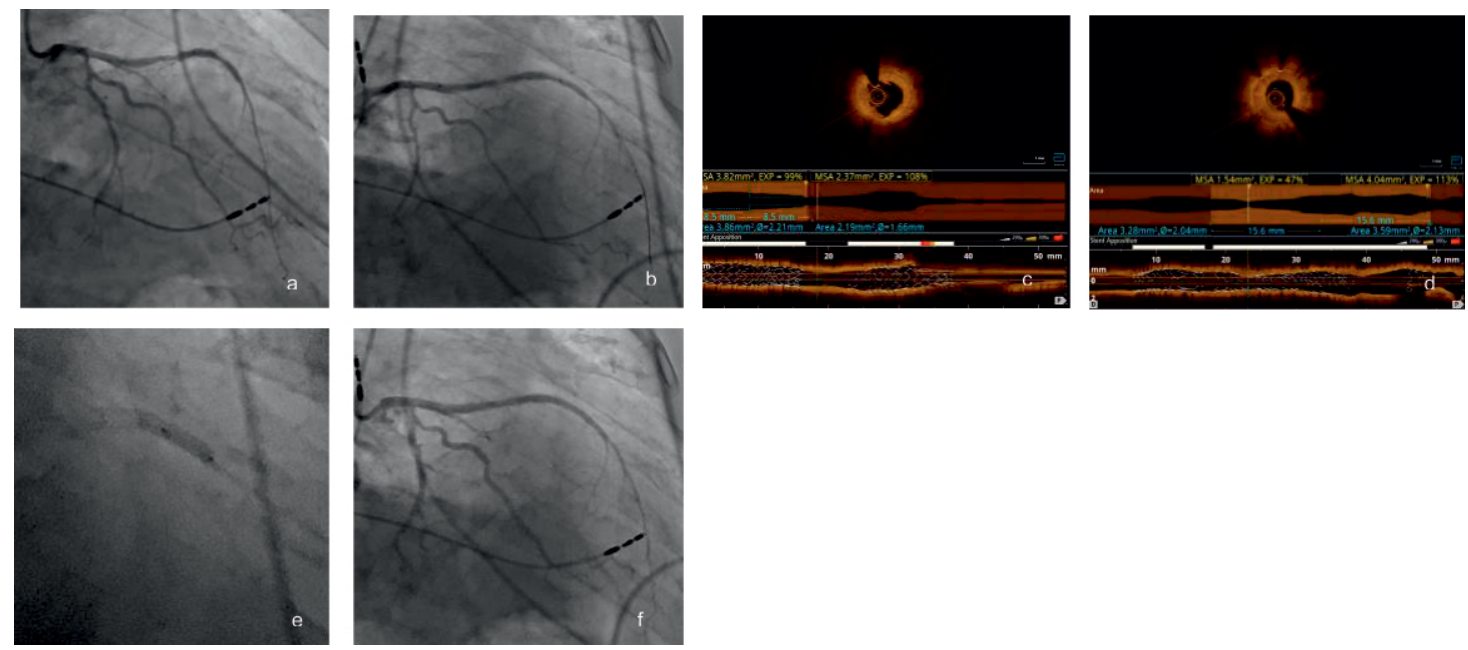

Figure 2. 63 y.o. male with a primary medical history of stage III Non-Small Cell Lung cancer, KRAS+ previously treated with Carboplatin, Paclitaxel, Trametinib with concurrent radiotherapy lung cancer with hypertension, hyperlipidemia, permanent pacemaker (PPM) and with refractory radiation induced CAD (Fig. 2a), optical coherence tomography OCT (Fig. 2b) showed severe instent restenosis fibrous (Fig. 2c) or fibrofatty (Fig. 2d) and underwent additional plain old balloon angioplasty (POBA) and PCl (Fig. 2e) with good immediate results (Fig. 2f).

cardiac fields involved. Additional confounding factors are the antineoplastic agents (chemotherapy and immunotherapy) that can be associated with vascular toxicity and progressive atherosclerosis.

\section{Effects of chemotherapy}

While the field of cardio-oncology is defined by cardiotoxicity in patients treated with anthracyclines and cardiac troponin $\mathrm{T}(\mathrm{TnT})$ elevation - dose dependent indicates cardiotoxicity, and vascular toxicities started triggering increased interest, the effects of chemotherapy on patients who undergo $\mathrm{PCl}$ is yet to be defined. ${ }^{36}$ Myocardial infarction has been described in association with a number of chemotherapeutic agents with variable temporal and clinical presentation. The infusion of fluorouracil can mimic myocardial infarction in seconds to minutes after infusion of the therapy and the risk can linger days following therapy. 5-Fluorouracil-induced cardiotoxicity during chemotherapy for adenocarcinoma of the small bowel has been reported $^{37}$. Other chemotherapeutic agents associated with acute coronary syndrome include vincristine, rituximab, and cisplatin. The treatment of ACS should be similar to the patients that do not carry the cancer diagnosis.

\section{Effects of immunotherapy}

Immunotherapy harnesses the power of the body's immune system to treat cancer, started with the use of interleukin-2 for metastatic melanoma and renal carcinoma and was early recognized as associated with cardiotoxicity, including myocardial ischemia ${ }^{38}$. Novel therapies such as adoptive $T$ cell therapy (ACT), with $T$ cells isolated from the patient that are genetically engineered to express receptors that have a high affinity for specific tumor antigens or chimeric antigen receptors $^{39}$ have been reported to have off-target mediated cardiotoxicity. While myocarditis was the primordial reported toxicity and main concern, other cardiotoxicities presenting with hypotension, tachycardia, arrythmias, LV dysfunction, cardiac arrest, and cardiac injury as reflected by the troponin elevation have been reported ${ }^{40}$. While a recent study showed $79 \%$ of patients will have left ventricular dysfunction and can present with global or regional wall motion abnormalities ${ }^{4}$. This clinical picture could be confused with myocardial infarction and should be evaluated as such until proven otherwise with the appropriate clinical and diagnostic testing such as EKG, troponin, and in patients with previous coronary artery disease diagnostic cardiac catheterization.

\section{Adapting Percutaneous Coronary Interventions and Outcome Reporting to Cancer Type \\ Hematologic Malignancy}

Hematologic malignancies comprised nearly $20 \%$ of all new cases in 2019 with leukemia being amongst the most common making up $7 \%$ of new diagnoses ${ }^{42}$. These cancers can lead to significant thrombocytopenia and platelet dysfunction which can increase the risk of major bleeding complications during procedures such as $\mathrm{PCl}^{43}$. In a study by Mohammed et. al from the NIS 
database, those with leukemia had statistically significant increased risk of bleeding $(p<.00 \mathrm{I})$ at $5.6 \% \mathrm{com}$ pared to $5.3 \%$ in those without leukemia ${ }^{44}$. Further sub-analysis showed CML patients had the highest risk of bleeding complications with OR of 1.20 [1.05-1.37; $\mathrm{P}<.007]$ which was thought to be secondary to the older age and chemotherapeutic agents used to treat this leukemic group, with tyrosine-kinase inhibitors (TKl's) associated with an increased bleeding risk ${ }^{45}$. Patients experiencing STEMI with a diagnosis of hematological malignancy were at a heightened risk for gastrointestinal bleeding with $3.1 \%$ of these patients having a bleed compared to $2.4 \%$ of other hospitalized patients without hematological malignancy with a $\mathrm{P}$ value of $0.00 \mathrm{I}^{46}$. This is despite the fact that just $48 \%$ of leukemic patients underwent coronary revascularization compared to $66 \%$ in the control population ${ }^{46}$.

The use of angiography for patients who presented with ACS (NSTEMI or STEMI) was $17.5 \%$ and $40 \%$ of the time respectively with only $5.3 \%$ and $30 \%$ receiving coronary intervention ${ }^{17}$. Medical management was incomplete with less than half of patients receiving the appropriate antiplatelet, anticoagulant, and/or statin therapy of which lead to an increase of in-hospital and I-year mortality of $22 \%$ and $59 \%$ for NSTEMI and STEMI respectively ${ }^{17}$. Outcome data was worse post- $\mathrm{PCl}$, which were primarily observed in AML with mortality odds-ratios of 5.38 in these cases without significance found in the other broad leukemia types ${ }^{14}$. However, based on this report many of these complications were related to non-cardiac complications such as bleeding and stroke with an insignificant difference in cardiac complication between leukemic patients and those without leukemia ${ }^{14}$. This supports the notion that patients with leukemia are at a predisposition of bleeding which could be explained by the predisposition to thrombocytopenia and platelet dysfunction.

Despite an increased risk of bleeding in leukemic patients, the prothrombotic nature of cancer can predispose even these patients to heightened risk of stent thrombosis. The incidence of stent thrombosis is rare in patients without cancer approaching just under $2 \%$ in those compliant with DAPT ${ }^{47}$. However, in the case of Sargsyan et. al, the presence of undiagnosed APML there appears to be an association between cancer leading to stent thrombosis of multiple coronary arteries and stents which lead to mortality. ${ }^{48}$ Those afflicted with polycythemia vera (PV) undergoing $\mathrm{PCl}$ experience both stent re-stenosis and stent thrombosis secondary to the proliferative and thrombotic nature of the disease ${ }^{49}$. It may be reasonable to screen patients for PV in the right clinical circumstance as $16 \%$ of patients with PV can present with arterial thrombosis based on a cohort of patients with $\mathrm{PV}^{49}$. Overall, mortality in these patients was also worse compared to controls without hematologic malignancy which was supported by several studies with in-hospital mortality ranging from 7.4 to $15 \%{ }^{14,44,46}$ Conclusions regarding these outcomes are difficult to draw with a lack of randomized control trials. However, this can be partially explained by previously mentions of the lack of GDMT in these patients compared to their non-malignant counterparts such as decreased use of DAPT and coronary revascularization.

The second most common hematologic malignancy, lymphoma, makes up 3\% to $4 \%$ of all cancers worldwide based on cancer registry data ${ }^{50-52}$. The treatments designated for this cancer can lead to significant cardiovascular disease as described previously with the use of mediastinal radiation in patients with lymphoma. A NIS study of patients who underwent $\mathrm{PCl}$ shows that approximately $0.25 \%$ of patients who underwent coronary intervention had a diagnosis of lymphoma observed in a 10 -year period with the prevalence increasing steadily since $2004^{53}$. These patients were also found to have less cardiovascular co-morbidities as those without lymphoma ${ }^{53}$. Multivessel revascularization with bare metal stents were more frequent in patients with lymphoma with more intravascular testing of disease as well as the use of left ventricular assist devices (LVAD) such as intra-aortic balloon pump (IABP) as patients with lymphoma were more likely to present with cardiogenic shock ${ }^{53}$. In congruence with leukemia patients with lymphoma, specifically Hodgkin's lymphoma, had higher rates of complications and in-hospital mortality after $\mathrm{PCl}$ with the cause being higher vascular and bleeding complications with odds ratios of I.I I (I.05I.I8) and I.I2 (I.06-I.19) respectively with the odds of in-hospital mortality approaching an increase of $39 \%$ (OR I.39 (I.25-I.54)) $)^{53}$. After adjusting for baseline risk factors, those with Non-Hodgkin's lymphoma did not see a significant increase in bleeding, vascular complications, or in-hospital mortality which suggests the co-morbidity of Hodgkin's lymphoma may portend a worse outcome for patients experiencing acute coronary syndrome undergoing revascularization ${ }^{53}$. All hematologic malignancies had a predisposition toward $\mathrm{TIA} /$ stroke after undergoing $\mathrm{PCl}$ in the current literature ${ }^{14,53}$. The mechanism for these clinical outcomes is 
only rudimentarily understood and there is a need for further study.

\section{Solid Tumors}

Approximately $\mathrm{I}$ in 10 patients who underwent $\mathrm{PCl}$ had an active or history of the four most common solid tumors (prostate, breast, colon, and lung) with these patients having worse in-hospital mortality or complications compared to those without cancer ${ }^{13}$. While patients with cancer and cardiovascular disease are the focus of clinical research in many centers in the world, there still is paucity of studies to draw from guidelines. We have commented on the most up to date literature for each cancer type and the optimal revascularization strategy based on current data.

\section{Prostate cancer}

Prostate cancer is the most commonly diagnosed cancer in men for the year of 2019 with $20 \%$ of new cancer diagnoses attributed to the prostate ${ }^{42}$. An inpatient analysis of patients from the United States of America with cancer and acute myocardial infarction reveals it is one of the most common cancer types with $16.5 \%$ of patients having a current diagnosis of prostate cancer ${ }^{54}$. The incidence and prevalence of those with prostate cancer who experience acute coronary syndrome will continue to have significant impact on our health care system with important clinical decisions to be made on appropriate treatment.

Medical management has been the cornerstone of treatment in this population with approximately $30 \%$ of these patients being managed medically compared to just $12 \%$ of those without cancer ${ }^{54}$. The mortality of these patients ranged from $7.5 \%$ to $13.5 \%$ depending if metastasis were present with significant mortality in the metastatic group with OR of $1.87(\mathrm{I} .7 \mathrm{I}, 2.03)^{54}$. The proportion of patients undergoing PCl world-wide with a current or historical diagnosis of prostate cancer ranges from 18-27\% dependent on the population studied and was commonly among the top 3 cancer diagnosis amongst these populations ${ }^{13,55-57}$. An active diagnosis of prostate cancer was associated with an approximately 10\% increase in the use of bare metal stent compared to those without cancer or a history of prostate cancer ${ }^{13}$. In the absence of metastatic disease, performing $\mathrm{PCl}$ on patients with active or a history of prostate cancer did not result in increased mortality compared to those without cancer in multiple studies ${ }^{13,54}$.
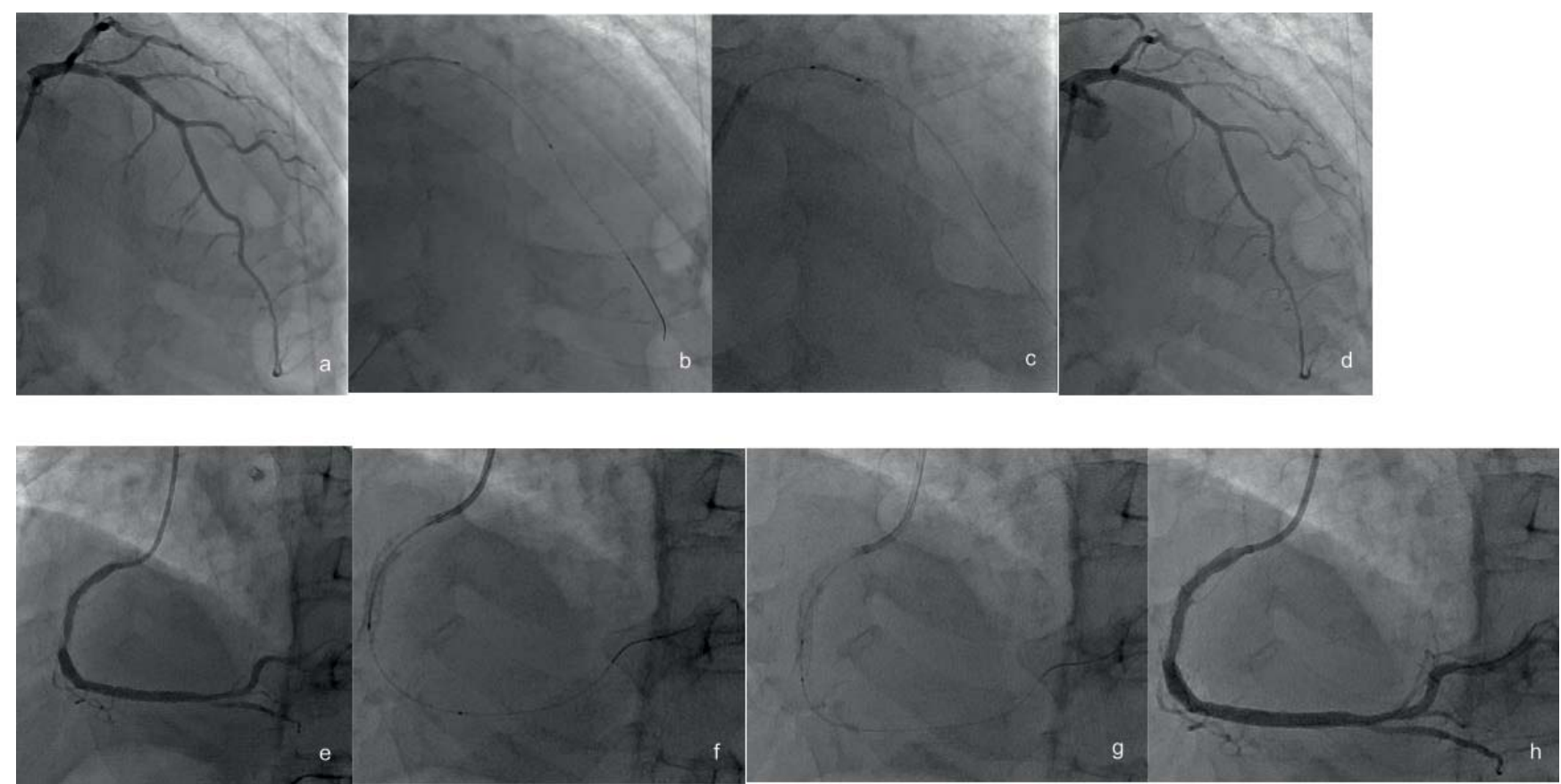

Figure 3. 78 y.o. male with essential thrombocytosis, CAD, atrial fibrillation admitted to the hospital for gastro-intestinal hemorrhage and chest pain/ NSTEMI. Coronary angiogram revealed an ulcerated plaque in the LAD (Fig. 3a) confirmed by IVUS (Fig. 3b) stented with a $4.0 \times 16 \mathrm{~mm}$ Synergy drugeluting stent with results optimized by post dilatation with a $4 \times 12 \mathrm{~mm} \mathrm{NC}$ Emerge balloon (Fig. 3c) and IVUS with also good final angiographic result (Fig. 3d). Right coronary artery had significant in-stent restenosis (ISR) (Fig. 3e) confirmed by IVUS (Fig. 3f) treated with POBA (Fig. 3g) as already patient had multiple stent layers with good IVUS and angiographic result (Fig. 3h). Prostate cancer. 
The most important clinical non-mortality based concern in these patients is complications from vascular access and bleeding risk as these appear to be more common in those with active prostate can$\mathrm{cer}^{13}$. The bleeding risk was associated with OR of I.56 $(1.47,1.65)$ when there was an active diagnosis of prostate cancer ${ }^{54}$. The presence of metastasis was magnified this risk with OR of $2.31(2.16,2.47)$ in those with prostate metastasis compared to 1.23 ( 1.18 , I.29) in those without metastases. Based on current literature, patients undergoing $\mathrm{PCl}$ with a history of prostate cancer are not at an increased risk of cardiac or non-cardiac mortality, but caution should be taken when approaching vascular access. The current expert consensus, on access in the cancer population would be the use of a micro-puncture kit and the use of radial access when appropriate to reduce vascular complications and bleeding risk which can be extrapolated to prostate cancer patients ${ }^{58}$.

\section{Breast cancer}

In the study by Darby et al., it was established that there was a $7.4 \%$ increase per gray $(95 \% \mathrm{Cl}, 2.9-14.5)$ of the rate of major coronary event in patients who received radiotherapy, with those irradiated for left breast having a higher rate than those irradiated for right breast ${ }^{28}$. The pathophysiology of breast cancer and its effect on developing cardiovascular disease is not well understood but in a retrospective analysis of NIS patients those with non-metastatic breast cancer does not appear to have an increased effect on mortality and MACCE with OR of $0.92,95 \% \mathrm{Cl} 0.82-1.02)^{59}$. The antineoplastic agents such as chemoradiotherapy appear to be the driving force of cardiovascular disease in breast cancer patients. In acute coronary syndrome, approximately $75 \%$ of breast cancer patients underwent revascularization with just $27 \%$ receiving $\mathrm{PCl} 59$. Utilization of revascularization in breast cancer patients In those with metastatic disease, the risk of MACCE, mortality, and bleeding were approximately 2 in each category ${ }^{59}$. Metastatic disease should be approached with significant caution and a multidisciplinary team as well as patient wishes should be considered when performing intervention in patients with breast cancer and metastatic disease experiencing coronary events. In the event of a ST elevation myocardial infarction (STEMI), there was underutilization of $\mathrm{PCl}$ with only $31 \%$ of patients receiving this revascularization technique, leading to an in-hospital mortality of $28 \%$ in patients not receiving $\mathrm{PCl}^{60}$. There was a $20 \%$ decrease in mortality in patients who underwent $\mathrm{PCl}$ after experiencing a STEMI ${ }^{60}$. Those with a history of breast cancer were also at a greater risk of developing heart failure with HR of 1.33 (95\% CI I.II-I.58 $p=.0016)$ than those without breast cancer HR $1.07(95 \% \mathrm{Cl}$ I.02-I.12 $p=.014)$ after acute myocardial infarction. This in part may be explained by the decreased use of revascularization in patients with breast cancer ${ }^{61}$.

Procedural considerations in cancer patients is important because of a heightened risk in some cancer populations toward bleeding. However, the use of radial access is preferred in patients with a history of breast cancer treatment as there is no added risk to increased complications such as lymphedema according to current literature ${ }^{62}$. In the event that radial access is not feasible, the use of alternative access is safe in breast cancer patients and in non-metastatic disease there is not an increased risk of procedural related bleeding with OR of $1.07(95 \% \mathrm{Cl} 0.99-\mathrm{I} .17)^{54}$.

\section{Colon cancer}

The improvement of screening and prevention of colorectal cancer (CRC has led to a 3\% decline annually in its incidence ${ }^{63}$. However, despite this colorectal cancer made up 17\% of new diagnosed cancer cases in 2019.42 This poses a significant public health risk and little is known about the impact CRC plays on the cardiovascular system but is thought to have a negative impact with CRC with $26 \%$ of patients experiencing some form of cardiovascular disease ${ }^{15}$. There is even less data on the appropriate management strategy of coronary intervention for those afflicted with active CRC. Similar to other solid tumors, metastatic CRC increased the risk of in-hospital mortality with $O R$ of $2.31(2.07,2.58)$ in patients who experienced $A_{C S}^{54}$. The reason for this is not well understood but could be due to the increased occurrence of complicating factors such as acute renal syndrome and thrombocytopenia which argues in favor of the importance of multidisciplinary decision-making ${ }^{13}$.

In patients without metastatic disease, the rate of procedural complication was the most abundant in colon cancer with an OR of $2.17(95 \% \mathrm{Cl}$ I.90-2.48) for any complication I3. Bleeding risk was the highest of any group with OR of $3.15(2.95,3.37)$ and $3.65(95 \%$ Cl 3.07-4.35) found in multiple studies /3,54. CRC in the absence of metastasis did not independently increase the in-hospital mortality with OR of I.39, (95\% $\mathrm{Cl} 0.99-1.95)^{13}$. The number of patients between $200 \mathrm{I}$ to $201 \mathrm{I}$ with colon cancer who experienced a ST elevation myocardial infarction was 9,944 with $17.3 \%$ of 
these patients not being treated with percutaneous coronary leading to a $32 \%$ rate of in-hospital mortality with mortality rates dropping to just over $10 \%$ for revascularization ${ }^{60}$. Utilizing $\mathrm{PCl}$ during an acute STEMI is critical even in those with an active colon cancer as these studies suggest a $10.7 \%$ rate of mortality without appropriate revascularization at one year ${ }^{60}$. However, there are limitations in these studies as they are observational without randomization and could suffer from other confounding biases. In the absence of metastatic disease based on current literature, coronary revascularization should be pursued and is safe in those with CRC.

\section{Lung cancer}

In a sample of $>6$ million percutaneous coronary procedures between 2004 and 2014, approximately 46,000 patients had a diagnosis of active or historical lung cancer with the crude in-hospital mortality for the total population approaching $10 \%$ of these patients with OR approaching I.65 (95\% Cl I.32-2.05) and $2.8 \mathrm{I}(95 \% \mathrm{Cl}$ 2.37-3.34) of historical and active diagnoses respectively ${ }^{13}$. The complication rate of active lung cancer was increased with a predisposition of bleeding (OR I.79 (95\% Cl I.56-2.05)). Metastasis amplified the mortality risk with adjusted OR of $3.94(\mathrm{Cl} 95 \% 3.04-5 . \mathrm{II})$ and an increase in bleeding risk (OR $2.33(\mathrm{Cl}$ 95\% $1.92-$ $2.83)^{13}$. Patients who presented with metastatic disease were less likely to undergo coronary intervention in the setting of acute myocardial infarction ${ }^{13,60}$. The utilization of percutaneous coronary intervention in patients who presented with ACS were less likely to receive GDMT or revascularization. Those presenting with STEMI, received $\mathrm{PCl}$ just $20 \%$ of the time with a mortality rate approaching $42 \%$ in those who did not undergo percutaneous revascularization. ${ }^{60}$ However, only those with local treatment with radiotherapy experienced cardiac-specific mortality based on available SEER data ${ }^{64}$. This increase in in-hospital mortality could be secondary to poor prognostic features of lung cancer or the high risk of clinically significant bleeding.

In similar fashion to other types of solid tumors, MACCE and mortality were elevated with a diagnosis of lung cancer with a two-fold increase in the lung cancer group with $\mathrm{OR}$ of $2.38,95 \% \mathrm{Cl}(2.3 \mathrm{I}-2.45$ and $2.7 \mathrm{I}, 95 \% \mathrm{Cl}(2.65-2.80)$, respectively. ${ }^{59}$ There is currently limited data on the study directed at individual cancers and much of the data are retrospective studies and sub-analysis of larger studies. Further study is needed to address the needs of these patients.

\section{CONCLUSION}

The modern interventional onco-cardiologist faces numerous challenges when managing CVD in patients with both active and past cancer. These patients often present with comorbidities that in a "traditional" cardiovascular population would've been considered at least relative contraindications to invasive management. In particular current evidence suggests improved outcomes following invasive management of ACS in cancer patients despite a higher risk of complications compared to non-cancer patients. Furthermore, specific types of cancer present individual challenges, an aspect which needs to be taken into consideration in further longitudinal studies.

\section{Conflict of interest: none declared.}

\section{References}

I. Curtin SC. Trends in Cancer and Heart Disease Death Rates Among Adults Aged 45-64: United States, 1999-2017:9.

2. Mozaffarian D, Benjamin EJ, Go AS, et al. Heart Disease and Stroke Statistics-2016 Update. :323.

3. Kushi LH, Doyle C, McCullough M, et al. American Cancer Society guidelines on nutrition and physical activity for cancer prevention: Reducing the risk of cancer with healthy food choices and physical activity. CA Cancer J Clin. 2012;62(I):30-67. doi: 10.3322/caac.20 I40

4. Koene RJ, Prizment AE, Blaes A, Konety SH. Shared Risk Factors in Cardiovascular Disease and Cancer. Circulation. 20 I 6; I 33(I I): I I04I I|4. doi: I0.1 I6I/CIRCULATIONAHA. I I5.020406

5. Kivimäki M, Kuosma E, Ferrie JE, et al. Overweight, obesity, and risk of cardiometabolic multimorbidity: pooled analysis of individuallevel data for 120813 adults from 16 cohort studies from the USA and Europe. Lancet Public Health. 2017;2(6):e277-e285. doi:10.1016/ S2468-2667(17)30074-9

6. Freisling $\mathrm{H}$, Viallon $\mathrm{V}$, Lennon $\mathrm{H}$, et al. Lifestyle factors and risk of multimorbidity of cancer and cardiometabolic diseases: a multinational cohort study. BMC Med. 2020;I8(I):5. doi:I0.II86/s I2916019-1474-7

7. Dhalwani NN, Zaccardi F, O'Donovan G, et al. Association Between Lifestyle Factors and the Incidence of Multimorbidity in an Older English Population. J Gerontol A Biol Sci Med Sci. Published online July 28, 2016:glw|46. doi:I0.1093/gerona/glwl46

8. Wikström K, Lindström J, Harald K, Peltonen M, Laatikainen T. Clinical and lifestyle-related risk factors for incident multimorbidity: 10 year follow-up of Finnish population-based cohorts 1982-2012. Eur J Intern Med. 20I5;26(3):2II-2I6. doi:10.1016/j.ejim.20I5.02.0I2

9. Mounce LTA, Campbell JL, Henley WE, Tejerina Arreal MC, Porter I, Valderas JM. Predicting Incident Multimorbidity. Ann Fam Med. 2018;16(4):322-329. doi:10.1370/afm.227I

10. Melis R, Marengoni A, Angleman S, Fratiglioni L. Incidence and Predictors of Multimorbidity in the Elderly: A Population-Based Longitudinal Study. Scuteri A, ed. PLoS ONE. 2014;9(7):el03I 20. doi: I0.137I/journal.pone.0103120

II. Xu X, Mishra GD, Dobson AJ, Jones M. Progression of diabetes, heart disease, and stroke multimorbidity in middle-aged women: A 20-year cohort study. Steinhubl SR, ed. PLOS Med. 2018;15(3):el0025I6. doi:I0.137|/journal.pmed.1002516

12. Yusuf SW, Sarfaraz A, Durand J-B, Swafford J, Daher IN. Management and outcomes of severe aortic stenosis in cancer patients. Am Heart J. 20I I; I6I (6): I I25-II32. doi: I0.10 I6/j.ahj.20II.03.0I3

13. Potts JE, Iliescu CA, Lopez Mattei JC, et al. Percutaneous coronary intervention in cancer patients: a report of the prevalence and outcomes in the United States. Eur Heart J. 2019;40(22):1790-1800. 


\section{doi:10.1093/eurheartj/ehy769}

14. Potts J, Mohamed MO, Lopez Mattei JC, et al. Percutaneous coronary intervention and in-hospital outcomes in patients with leukemia: a nationwide analysis. Catheter Cardiovasc Interv. Published online August 13, 2019:ccd.28432. doi:10.1002/ccd.28432

15. Al-Kindi SG, Oliveira GH. Prevalence of Preexisting Cardiovascular Disease in Patients With Different Types of Cancer. Mayo Clin Proc. 2016;9I(I):8I-83. doi:10.1016/j.mayocp.2015.09.009

16. van Kruijsdijk RC, van der Graaf Y, Koffijberg H, et al. Cause-specific mortality and years of life lost in patients with different manifestations of vascular disease. Eur J Prev Cardiol. 2016;23(2):160-169. doi: I0.I I 77/20474873|4566998

17. Park JY, Guo W, Al-Hijji M, et al. Acute coronary syndromes in patients with active hematologic malignancies - Incidence, management, and outcomes. Int J Cardiol. 2019;275:6-12. doi:10.1016/j.ijcard.2018.10.008

18. Yusuf SW, Daraban N, Abbasi N, Lei X, Durand J-B, Daher IN. Treatment and Outcomes of Acute Coronary Syndrome in the Cancer Population. Clin Cardiol. 2012;35(7):443-450. doi:10.1002/ clc. 22007

19. Navi BB, Reiner AS, Kamel H, et al. Risk of Arterial Thromboembolism in Patients With Cancer. J Am Coll Cardiol. 2017;70(8):926938. doi:I0.1016/j.jacc.2017.06.047

20. Liu VY, Agha AM, Lopez-Mattei J, et al. Interventional Cardio-Oncology: Adding a New Dimension to the Cardio-Oncology Field. Front Cardiovasc Med. 2018;5:48. doi: 10.3389/fcrm.2018.00048

21. Raphael CE, Spoon DB, Bell MR, et al. Effect of Preprocedural Thrombocytopenia on Prognosis After Percutaneous Coronary Intervention. Mayo Clin Proc. 2016;91(8):1035-1044. doi:10.1016/j. mayocp.2016.05.008

22. Ayoub K, Marji M, Ogunbayo G, et al. Impact of Chronic Thrombocytopenia on In-Hospital Outcomes After Percutaneous Coronary Intervention. JACC Cardiovasc Interv. 2018; I I (I8): I862-I868. doi:10.1016/j.jcin.2018.05.033

23. Iliescu C, Balanescu DV, Donisan T, et al. Safety of Diagnostic and Therapeutic Cardiac Catheterization in Cancer Patients With Acute Coronary Syndrome and Chronic Thrombocytopenia. Am J Cardiol. 2018; I22(9): I465-I470. doi:I0.10 |6/j.amjcard.2018.07.033

24. Cuomo JR, Javaheri SP, Sharma GK, Kapoor D, Berman AE, Weintraub NL. How to prevent and manage radiation-induced coronary artery disease. Heart. 20I8;104(20):1647-1653. doi:10.1/36/ heartjnl-20I7-3I2I23

25. Boekel NB, Schaapveld M, Gietema JA, et al. Cardiovascular Disease Risk in a Large, Population-Based Cohort of Breast Cancer Survivors. Int J Radiat Oncol. 2016;94(5):106I-1072. doi:10.1016/j. ijrobp.2015.II.040

26. McGale P, Darby SC, Hall P, et al. Incidence of heart disease in 35,000 women treated with radiotherapy for breast cancer in Denmark and Sweden. Radiother Oncol. 2011;100(2):167-175. doi:10.1016/j.radonc.2011.06.016

27. van Nimwegen FA, Schaapveld M, Cutter DJ, et al. Radiation DoseResponse Relationship for Risk of Coronary Heart Disease in Survivors of Hodgkin Lymphoma. J Clin Oncol. 2016;34(3):235-243. doi:I0.I200/JCO.20I5.63.4444

28. Darby SC, Ewertz M, McGale P, et al. Risk of Ischemic Heart Disease in Women after Radiotherapy for Breast Cancer. N Engl J Med. 20 I3;368(I I):987-998. doi:I0.1056/NEJMoa I 209825

29. Beohar N, Kirtane AJ, Blackstone E, et al. Trends in Complications and Outcomes of Patients Undergoing Transfemoral Transcatheter Aortic Valve Replacement. JACC Cardiovasc Interv. 2016;9(4):355363. doi:I0.1016/j.jcin.20I5.10.050

30. McEniery PT, Dorosti K, Schiavone WA, Pedrick TJ, Sheldon WC. Clinical and angiographic features of coronary artery disease after chest irradiation. Am J Cardiol. 1987;60(13): 1020-1024. doi:10.1016/0002-9149(87)90345-6

31. Orzan F, Brusca A, Conte MR, Presbitero P, Figliomeni MC. Severe coronary artery disease after radiation therapy of the chest and mediastinum: clinical presentation and treatment. :5.
32. Reed GW, Rossi JE, Masri A, et al. Angiographic predictors of adverse outcomes after percutaneous coronary intervention in patients with radiation associated coronary artery disease. Catheter Cardiovasc Interv. 2019;94(3). doi:10.1002/ccd.28107

33. Glanzmann C, Kaufmann P, Jenni R, Hess OM, Huguenin P. Cardiac risk after mediastinal irradiation for Hodgkin's disease. Radiother Oncol. 1998;46(I):5I-62. doi:I0.10I6/S0I67-8I40(97)00I25-4

34. van Rosendael AR, Daniëls LA, Dimitriu-Leen AC, et al. Different manifestation of irradiation induced coronary artery disease detected with coronary computed tomography compared with matched nonirradiated controls. Radiother Oncol. 2017; I25(I):55-6I. doi: I0.1016 /j.radonc.2017.09.008

35. Liang JJ, Sio TT, Slusser JP, et al. Outcomes After Percutaneous Coronary Intervention With Stents in Patients Treated With Thoracic External Beam Radiation for Cancer. JACC Cardiovasc Interv. 20I4;7(I2): I4|2-I420. doi:I0.10|6/j.jcin.20|4.05.035

36. Floyd JD, Nguyen DT, Lobins RL, Bashir Q, Doll DC, Perry MC. Cardiotoxicity of Cancer Therapy. J Clin Oncol. 2005;23(30):7685-7696. doi:I0.1200/JCO.2005.08.789

37. Bagai RK, Spiro TP, Daw HA. 5-Fluorouracil-Induced Cardiotoxicity During Chemotherapy for Adenocarcinoma of the Small Bowel. 2009;3(4):4.

38. Asnani A. Cardiotoxicity of Immunotherapy: Incidence, Diagnosis, and Management. Curr Oncol Rep. 2018;20(6):44. doi:10.1007/ sII9|2-018-0690-I

39. Robbins PF, Morgan RA, Feldman SA, et al. Tumor Regression in Patients With Metastatic Synovial Cell Sarcoma and Melanoma Using Genetically Engineered Lymphocytes Reactive With NY-ESO-I. J Clin Oncol. 20II;29(7):917-924. doi:10.1200/JCO.2010.32.2537

40. Davila ML, Riviere I, Wang X, et al. Efficacy and Toxicity Management of 19-28z CAR T Cell Therapy in B Cell Acute Lymphoblastic Leukemia. : 12 .

41. Escudier M, Cautela J, Malissen N, et al. Clinical Features, Management, and Outcomes of Immune Checkpoint Inhibitor-Related Cardiotoxicity. Circulation. 2017;136(2I):2085-2087. doi:I0.1 I6I/CIRCULATIONAHA.II7.03057I

42. Siegel RL, Miller KD, Jemal A. Cancer statistics, 2019. CA Cancer J Clin. 2019;69(I):7-34. doi:I0.3322/caac.2I55 I

43. Kwok CS, Rao SV, Myint PK, et al. Major bleeding after percutaneous coronary intervention and risk of subsequent mortality: a systematic review and meta-analysis. Open Heart. 20I4; I (I):e00002I. doi:I0.1 I36/openhrt-2013-00002 I

44. Mohamed MO, Lopez-Mattei JC, Parwani P, et al. Management strategies and clinical outcomes of acute myocardial infarction in leukaemia patients: Nationwide insights from United States hospitalisations. Int J Clin Pract. Published online January 20, 2020. doi: I0.1 I I I/ ijcp. 13476

45. O'Brien SG, Guilhot F, Larson RA, et al. Imatinib Compared with Interferon and Low-Dose Cytarabine for Newly Diagnosed ChronicPhase Chronic Myeloid Leukemia. N Engl J Med. 2003;348(II):9941004. doi: I0.1056/NEJMoa022457

46. Patel G, Pancholy N, Thomas L, et al. Effect of Chronic Hematologic Malignancies on In-Hospital Outcomes of Patients With ST-Segment Elevation Myocardial Infarction. Am J Cardiol. 2019;124(3):349-354. doi:10.1016/j.amjcard.2019.04.049

47. Cutlip DE, Baim DS, Ho KKL, et al. Stent Thrombosis in the Modern Era: A Pooled Analysis of Multicenter Coronary Stent Clinical Trials. Circulation. 200I;103(15):1967-197I. doi:10.1161/0I. CIR.I03.15.1967

48. Rashidi A, Silverberg ML, Conkling PR, Fisher Sl. Thrombosis in acute promyelocytic leukemia. Thromb Res. 2013;13I(4):28I-289. doi:10.1016/j.thromres.2012.11.024

49. Tefferi A, Rumi E, Finazzi G, et al. Survival and prognosis among I 545 patients with contemporary polycythemia vera: an international study. Leukemia. 2013;27(9):1874-188I. doi:10.1038/leu.2013.163

50. Roman E, Smith AG. Epidemiology of lymphomas: Epidemiology and lymphomas. Histopathology. 201 I;58(I):4-14. doi:10.1 II I/j.13652559.2010.03696.x 
5I. Alexander DD, Mink PJ, Adami H-O, et al. The non-Hodgkin lymphomas: A review of the epidemiologic literature. Int J Cancer. 2007; I 20(SI2): I-39. doi: I0.1002/ijc.227|9

52. Li J, Smith A, Crouch S, Oliver S, Roman E. Estimating the prevalence of hematological malignancies and precursor conditions using data from Haematological Malignancy Research Network (HMRN). Cancer Causes Control. 2016;27(8):I0I9-1026. doi:I0.1007/sI0552016-0780-z

53. Borovac JA, Kwok CS, lliescu C, et al. Percutaneous Coronary Intervention and Outcomes in Patients With Lymphoma in the United States (Nationwide Inpatient Sample [NIS] Analysis). Am J Cardiol. 2019;।24(8): I 190-II97. doi:I0.1016/j.amjcard.2019.07.015

54. Bharadwaj A, Potts J, Mohamed MO, et al. Acute myocardial infarction treatments and outcomes in 6.5 million patients with a current or historical diagnosis of cancer in the USA. Eur Heart J. 2020;4 I (23):2 I83-2193. doi: |0.1093/eurheartj/ehz85 |

55. Landes U, Kornowski R, Bental T, et al. Long-term outcomes after percutaneous coronary interventions in cancer survivors: Coron Artery Dis. 2017;28(I):5-10. doi:10.1097/MCA.0000000000000429

56. Wang F, Gulati R, Lennon RJ, et al. Cancer History Portends Worse Acute and Long-term Noncardiac (but Not Cardiac) Mortality After Primary Percutaneous Coronary Intervention for Acute ST-Segment Elevation Myocardial Infarction. Mayo Clin Proc. 2016;9I(I2):I6801692. doi:10.1016/j.mayocp.2016.06.029

57. Tabata N, Sueta D, Yamamoto E, et al. Outcome of current and history of cancer on the risk of cardiovascular events following percutaneous coronary intervention: a Kumamoto University Malignancy and Atherosclerosis (KUMA) study. Eur Heart J - Qual Care Clin Outcomes. 20I8;4(4):290-300. doi:I0.1093/ehjqcco/qcx047
58. Iliescu C, Grines CL, Herrmann J, et al. SCAl expert consensus statement: Evaluation, management, and special considerations of cardio-oncology patients in the cardiac catheterization laboratory (Endorsed by the Cardiological Society of India, and Sociedad Latino Americana de Cardiologia Interve: SCAI Expert Consensus Statement. Catheter Cardiovasc Interv. 2016;87(5):895-899. doi:I0.1002/ ccd. 26375

59. Bharadwaj AS, Swamy PM, Mamas MA. Outcomes of percutaneous coronary interventions in cancer patients. Expert Rev Cardiovasc Ther. 2020; I8(I):25-32. doi:I0.1080/|4779072.2020.17/8493

60. Pothineni NV, Shah NN, Rochlani $\mathrm{Y}$, et al. Temporal trends and outcomes of acute myocardial infarction in patients with cancer. Ann Transl Med. Published online December 2017:482-482. doi: 10.21037/atm.2017.II.29

61. Gong IY, Yan AT, Ko DT, et al. Temporal changes in treatments and outcomes after acute myocardial infarction among cancer survivors and patients without cancer, 1995 to 2013: AMI During Cancer Survivorship. Cancer. 20 I8; I 24(6): I269-I278. doi:I0.I002/cncr.3 I I74

62. Yadav PK, Bagur R, Baquero GA, Gilchrist IC. Safety and Feasibility of Transradial Catheterization in Breast Cancer Survivors. JACC Cardiovasc Interv. 2015;8(4):639-64I. doi:I0.1016/j.jcin.2014.08.018

63. Siegel RL, Fedewa SA, Anderson WF, et al. Colorectal Cancer Incidence Patterns in the United States, 1974-20I3. JNCI J Natl Cancer Inst. 2017;109(8). doi:10.1093/jnci/djw322

64. Abdel-Rahman $O$. Risk of cardiac death among cancer survivors in the United States: a SEER database analysis. Expert Rev Anticancer Ther. 20I7; I7(9):873-878. doi:I0.1080/|4737|40.2017.1344099. 